\title{
A case of cervical epidural hematoma with symptom aggravation after improper anticoagulant therapy
}

Ryuta Imamura*, Takeshi Arizono, Akihiko Inokuchi, Takahiro Hamada and Kenjiro Nishida

Department of Orthopaedic Surgery, Kyushu Central Hospital, Fukuoka, Japan

\begin{abstract}
The advent of tissue plasminogen activator (tPA) has greatly advanced the treatment of cerebral infarction. tPA should be administered within $3-4.5$ hours after symptom onset, and thus tPA treatment may be initiated before definitive diagnosis. We present a rare case of spontaneous cervical spinal epidural hematoma in which the symptoms were aggravated by improper tPA administration after misdiagnosis.
\end{abstract}

\section{Introduction}

The advent of tissue plasminogen activator (tPA) has greatly advanced the treatment of cerebral infarction. tPA should be administered within 3-4.5 hours after symptom onset [1], and thus tPA treatment may be initiated before definitive diagnosis. We present a rare case of spontaneous cervical spinal epidural hematoma (SEH) in which the symptoms were aggravated by improper tPA administration after misdiagnosis. To our knowledge, there are only four reports of cervical SEH being treated incorrectly with $\mathrm{PA}$ in the English literature [2-5].

\section{Case report}

An 81-year-old woman developed paralysis of the right leg within 30 minutes after the onset of idiopathic neck pain. She was transported by ambulance to the emergency room (ER). ER examination revealed normal consciousness and a blood pressure of $198 / 85 \mathrm{mmHg}$. She could grasp her right hand but was unable to move the other muscles of her right upper and lower limbs. There were no sensory disturbances, and no cranial nerve signs. Brain CT and MRI did not reveal any lesions, except for old ischemic changes (Figure 1). Despite the absence of lesions, acute stroke could not be ruled out, and so tPA was administered.

One day after tPA administration, the patient developed left hypoalgesia in the area innervated by T1-T4. She could not sense urination, contract the anal sphincter, or grasp her right hand. Cervical spine MRI performed two days after symptom onset showed right-sided cervical SEH from C4-Th5. The patient was immediately
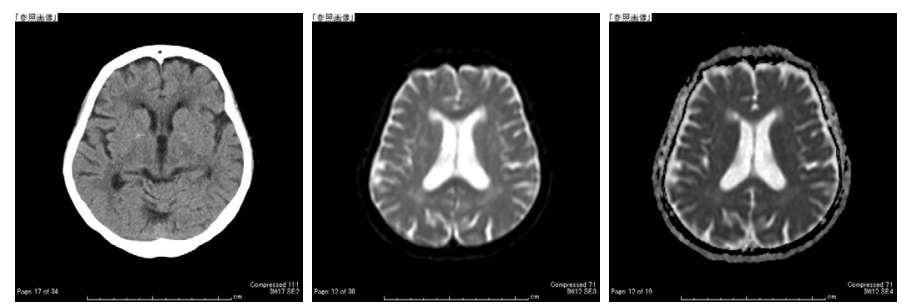

Figure 1. Brain CT showing the absence of any acute lesions such as hemorrhage. Brain MRI showing only chronic ischemic changes. A: Brain CT image; B: Diffusion-weighted image; C: apparent diffusion coefficient (ADC) map

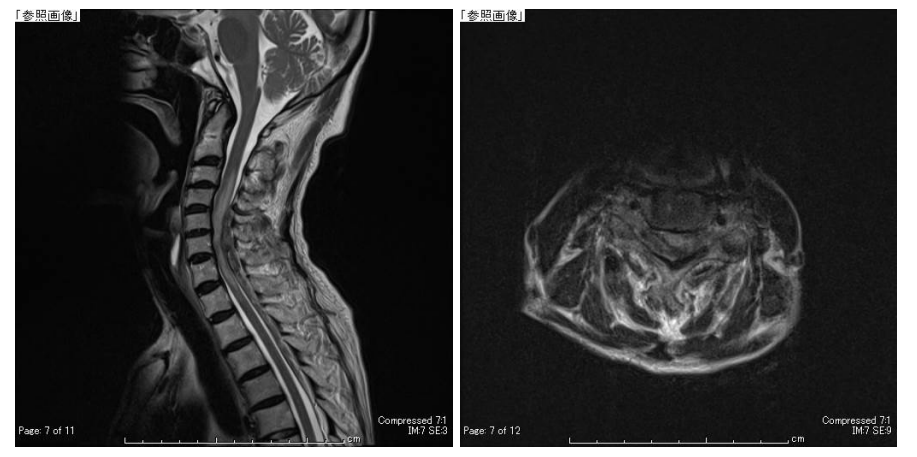

Figure 2. Preoperative MRI showing a heterogeneous extradural mass from the level of $\mathrm{C} 5$ to T5. The spinal cord is compressed by the extradural mass. A: T2-weighted sagittal image, $\mathrm{B}$ : T2-weighted transverse image at the level of C5

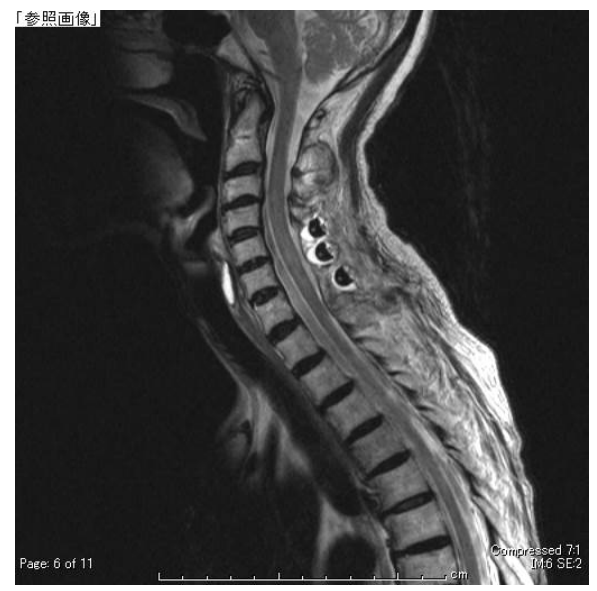

Figure 3. Postoperative sagittal T2-weighted MRI showing good decompression. The high intensity area in the spinal cord has almost disappeared.

*Correspondence to: Ryuta Imamura, 3-23-1 Shiobaru, Minami-ku, Fukuoka City, Fukuoka Prefecture, Japan, Tel: 092-541-4936, E-mail: mdgkn670@yahoo.co.jp

Key words: cervical epidural hematoma, tissue plasminogen activator, misdiagnosis Received: June 06, 2020; Accepted: June 19, 2020; Published: June 24, 2020 
transferred to our department. Manual muscle test scores were 0 for the right upper and lower limb muscles, except the deltoid and elbow flexors. The hematoma was immediately removed via laminoplasty. Postoperatively, the muscle strength gradually recovered. At 2 years postoperatively, the manual muscle test scores for the right upper and lower limb muscles were all 5 , and the grip power was $5 \mathrm{~kg}$ on the right and $16 \mathrm{~kg}$ on the left; the only sensory disturbance was a burning sensation in the right hand.

\section{Discussion}

Spontaneous SEH typically causes sensory and motor disturbances in accordance with the lesion level. Hemiparesis caused by cervical SEH might not be uncommon [3]. One study reported that six of 35 patients with SEH had hemiparesis [6], and a review reported that 17 of 613 patients with SEH exhibited Brown-Sequard syndrome [7].

SEH may be relatively frequently misdiagnosed. One study reported that nine of 138 patients $(6.5 \%)$ initially diagnosed with acute ischemic stroke and treated with tPA were misdiagnosed [2]. Another study concluded that patients with hemiparesis in the absence of cranial nerve signs should always have cervical spinal cord lesion included in the differential diagnoses [8]. However, the limited time before the initiation of tPA treatment forces a diagnosis to be made as soon as possible, which may increase the risk of misdiagnosis. The presence of neck or back pain before hemiparesis is an important indicator of a cervical spinal cord lesion $[3,4,6,7]$.

In our case, right hemiplegia without cranial nerve signs was observed in the ER. Although there were no abnormal findings on brain imaging, the physicians administered tPA because the symptoms were severe and the time limit for initiating tPA treatment was imminent. The symptoms worsened after tPA administration. However, full recovery of paralysis was achieved postoperatively. The neurological outcome depends on the time from the onset of symptoms to surgical decompression, and the level of preoperative neurological deficits $[6,9]$. Thus, misdiagnosis of SEH may result in a critical condition.

\section{Conclusion}

We presented a rare case of cervical SEH in which the symptoms were aggravated by improper tPA therapy due to misdiagnosis. Physicians should suspect cervical lesions in hemiplegic patients, especially if hemiparesis is preceded by neck or back pain.

\section{Acknowledgments}

We thank Kelly Zammit, BVSc, from Edanz Editing (www. edanzediting.com/ac), for editing a draft of this manuscript.

\section{References}

1. Hacke W, Kaste M, Bluhmki E, Brozman M, Dávalos A, et al. (2008) Thrombolysis with alteplase 3 to 4.5 hours after acute ischemic stroke. N Engl J Med 359: 1317-1329. [Crossref]

2. Kim MC, Kim SW (2018) Improper Use of Thrombolytic Agents in Acute Hemiparesis Following Misdiagnosis of Acute Ischemic Stroke. Korean J Neurotrauma 14: 20-23. [Crossref]

3. Morimoto T, Yoshihara T, Yakushiji Y, Eriguchi M, Hara H, et al. (2016) Worsening Cervical Epidural Hematoma After Tissue Plasminogen Activator Administration for Stroke Like Symptoms. Spine 41: E437-440. [Crossref]

4. Yurter A, Kaloostian P (2013) Spontaneous cervical epidural hematoma mimicking stroke: a new perspective on diagnosis and treatment. OJMN 3: 59-62.

5. Son S, Kang DH, Choi DS, Kim S-K, Lim BH, et al. (2012) A case of spontaneous spinal hematoma mimicking a stroke. Neurologist 18: 41-3. [Crossref]

6. Liao CC, Lee ST, Hsu WC, Chen LR, Lui TN, et al. (2004) Experiences in the surgical management of spontaneous spinal epidural hematoma. J Neurosurg 100: 38-54. [Crossref]

7. Kreppel D, Antoniadis G, Seeling W (2003) Spinal hematoma: a literature survey with meta-analysis of 613 patients. Neurosurg rev 26: 1-49. [Crossref]

8. Wang CC, Chang CH, Lin HJ, Kao-Chang Lin, Jinn-Rung Kuo (2009) Misdiagnosis of spontaneous cervical epidural hemorrhage. Eur Spine J 18: S210-2. [Crossref]

9. Groen RJ, van Alphen HA (1996) Operative treatment of spontaneous spinal epidural hematomas: a study of the factors determining postoperative outcome. Neurosurgery 39: 494-508. [Crossref]

Copyright: (C2020 Imamura R. This is an open-access article distributed under the terms of the Creative Commons Attribution License, which permits unrestricted use, distribution, and reproduction in any medium, provided the original author and source are credited. 